\title{
INVESTIGAÇÕES EM ACONSELHAMENTO GENÉTICO: IMPACTO DA PRIMEIRA NOTÍCIA - A REAÇÃO DOS PAIS À DEFICIÊNCIA
}

INVESTIGATIONS IN GENETICS COUNSELLING: THE IMPACT OF THE FIRST NOTIFICATION - PARENTAL REACTION TO A DEFICIENCY

\author{
Eucia B. L. Petean ${ }^{1} \&$ João M. de Pina Neto²
}

PETEAN EBL \& PINA NETO JM de. Investigações em aconselhamento genético: impacto da primeira notícia - a reação dos pais à deficiência. Medicina, Ribeirão Preto, 31: 288-295, abr./jun. 1998.

RESUMO: O presente trabalho procurou conhecer, junto aos pais de crianças portadoras de deficiência e/ou anomalias genéticas, qual o impacto causado pela notícia, suas reações e sentimentos. Participaram deste estudo dez (10) famílias, que foram encaminhadas ao Ambulatório de Genética Médica do Hospital das Clínicas da Faculdade de Medicina de Ribeirão Preto da Universidade de São Paulo para diagnóstico e orientação.

Os relatos mostraram que o impacto emocional da notícia é grande, desencadeando reações diversas, entre elas choque e agressividade. Culpa, negação e raiva são alguns dos sentimentos vivenciados pelos pais. A notícia é dada quase sempre de maneira inadequada, dificultando a compreensão do diagnóstico.

Pode-se concluir que, independentemente do quadro clínico, os pais sofrem o impacto da notícia de que seu filho é portador de deficiência e/ou anomalia genética.

O processo de sofrimento é agudo, passando os pais por um período de enlutamento pela perda do filho esperado.

UNITERMOS: Aconselhamento Genético. Família. Psicologia. Criança Excepcional.

\section{INTRODUÇÃO}

O nascimento de um filho é uma experiência única, faz parte do ciclo de vida de uma família e em muitos casos, representa a realização social e emocional da mulher, e o símbolo de masculinidade para o homem.

Durante o período gestacional, segundo Soifer ${ }^{(1)}$, ansiedades específicas são comuns e esperadas. O medo do parto prematuro, da morte do feto e de deficiência se fazem presentes.
O casal fantasia, cria expectativas, projeta em seus filhos anseios e desejos, esperando que se realize tudo o que haviam sonhado para si.

O nascimento, normalmente, marca uma época de alegrias. O filho é visto como fonte de sentimentos, de afetividade construtiva e gratificante para os pais ${ }^{(2)}$. Dá a certeza da realização do papel social, de missão cumprida, demonstrando, concreta e visivelmente, a união do casal.

O nascimento de uma criança diferente da esperada, portadora de deficiência, é traumático e 
desestruturador. Interrompe o equilíbrio familiar, todos os membros são afetados, o impacto é intenso e sua extensão indeterminada.

A literatura ${ }^{(3 / 6)}$ mostra que os sentimentos mais comuns, que os pais vivenciam então, são: choque, negação, raiva, tristeza e culpa, até que um novo tipo de equilíbrio se reestabeleça, permanecendo sempre um sentimento de tristeza, de mágoa que se manifestará e/ou se intensificará a cada novo fato. contar?

Como falar aos pais? O que contar? Quando

São questões que têm preocupado os profissionais que trabalham na área, ou os que, por motivos diversos, mantêm contato com essas famílias.

A maioria dos profissionais não se encontram preparados, técnica ou emocionalmente, para lidar com a situação. Sentem-se ansiosos, experimentam um desconforto, um sentimento de impotência, ao terem que comunicar a notícia aos pais.

De acordo com Regen et al. ${ }^{(7)}$ atitudes, tais como a omissão da informação, a minimização, a exacerbação do quadro clínico ou mesmo a informação dada de forma abrupta, sem que se espere o momento adequado, têm sido freqüentemente observadas. Para os autores é fundamental que os profissionais estejam bem preparados não só emocionalmente, mas, também, tecnicamente, para lidarem com esta situação.

A forma como a notícia é dada, o momento em que é dada e o tipo da linguagem utilizada podem comprometer a compreensão dos aspectos clínicos do problema, influenciar as expectativas dos pais em relação ao desenvolvimento físico e mental de seu filho, dificultar o estabelecimento dos vínculos afetivos, e exacerbar ou minimizar os conflitos intrapsíquicos e interpessoais existentes entre o casal.

Smith ${ }^{(8)}$ afirma que, "no meio de um trauma, parte das informações podem parecer distorcidas e confusas. Escutam-se palavras que nunca se ouviram antes, termos que descrevem alguma coisa que não se consegue compreender".

Sob o impacto da notícia, os pais podem distorcer as informações, percebendo-as como sendo negativas e destruidoras.

Vários estudos ${ }^{(7,9)}$ têm demonstrado que os pais só serão capazes de efetivamente assimilarem as orientações e de oferecerem os atendimentos necessários ao desenvolvimento da criança, quando o choque inicial, provocado pela notícia da deficiência do filho, passou. O período de choque é comumente considerado como de "enlutamento" pela perda do filho idealizado. Apenas após esta fase é que os pais tomam as providências necessárias para uma melhor perspectiva de vida da criança, passando a "aceitá-la", adotando posições mais realistas.

É primordial que os profissionais envolvidos na nova realidade de vida da família tenham amplo conhecimento de todo o processo pelo qual passam os pais, para que possam compreendê-los e dar-lhes o tempo necessário para assimilarem as informações e, principalmente, tomarem as decisões necessárias, com clareza e racionalidade.

Conhecer a percepção das famílias sobre como lhes foi dada a notícia, que reações tiveram frente ao fato, que sentimentos vivenciaram ou estão vivenciando, é fundamental para se compreender amplamente o processo de reestruturação.

É importante que os profissionais que atuam nos Serviços de Aconselhamento Genético estejam cientes de que dificilmente as famílias chegam, para iniciarem o processo, na fase de reestruturação. Encontram-se, ainda, sob o impacto da notícia, necessitando de apoio, compreensão e tempo para que possam vivenciar e elaborar todos os "fatos" ocorridos, bem como receber as informações necessárias.

Os Serviços de Aconselhamento Genético têm, entre seus vários objetivos, a definição do diagnóstico, informar a família sobre ele, sobre o prognóstico e sobre o risco de recorrência. Devem também orientar os pais quanto às características do desenvolvimento do filho e quais os atendimentos/tratamentos que se fazem necessários para o melhor desenvolvimento da criança.

A partir da vivência no acompanhamento de pais, durante o Aconselhamento Genético, e dos dados da literatura, propusemo-nos a realizar um estudo, tendo por objetivo acompanhar as famílias desde o momento em que iniciam o atendimento no Ambulatório de Genética até a alta, ou seja, até ter sido realizado o Aconselhamento Genético, visando compreender o processo psicológico pelo qual eles passam e qual a influência do Aconselhamento Genético em suas vidas.

No presente trabalho, apresentamos os dados referentes a três tópicos, abordados na primeira entrevista: impacto da notícia, sentimentos dos pais e suas reações frente à notícia.

\section{CASUÍSTICA E METODOLOGiA}

\subsection{Sujeitos}

\section{a) Seleção dos sujeitos}

As famílias foram contatadas ao chegarem ao Ambulatório de Genética para a primeira consulta 
médica. Na ocasião, expunham-se os objetivos da pesquisa e solicitava-se a participação da família. Obtida a concordância da família, procedia-se à primeira entrevista. Os relatos foram registrados nos roteiros, as entrevistas tiveram a duração média de uma hora e meia. Para a seleção de sujeitos não foram estabelecidos critérios quanto à idade, sexo, nível sócio-econômico ou tipo de anomalia.

\section{b) Caracterização dos sujeitos (amostra)}

Participaram da pesquisa dez (10) famílias, sendo que os filhos afetados que os levaram a procurar o Ambulatório de Genética distribuíram-se da seguinte forma: quanto ao sexo, são sete (07) homens, uma (01) mulher, um (01) natimorto com sexo indeterminado e outra família com dois (02) abortos espontâneos; quanto à posição das crianças na ordem dos nascimentos, somente três (03) são primogênitos (incluindo um (01) natimorto), quatro (04) crianças são o segundo filho, uma (01) é o quarto e uma (01) é o sétimo filho do casal.

Quanto ao nível de escolaridade, cinco (05) pais e seis (06) mães possuem primeiro grau incompleto; três (03) pais e duas (02) mães, primeiro grau completo; um (01) pai e uma (01) mãe, colegial completo; uma (01) mãe, colegial incompleto, e somente um (01) pai na amostra, possui curso superior completo.

No que se refere à ocupação, cinco (05) pais são empregados de firmas, três (03) são autônomos e um (01) não tem sua profissão declarada, quatro (04) mães exercem atividades fora de casa e as demais dedicam-se aos cuidados domésticos.

Em relação ao diagnóstico, três (03) crianças apresentavam Síndrome de Down; uma (01), Síndrome de Silver-Russel; uma (01), Síndrome de BeckwithWiedemann, uma (01), Distrofia Muscular Progressiva, Tipo Duchenne; uma (01), Sirenomelia; uma (01), Retardo do Desenvolvimento Neuropsicomotor (R.N.P.M.) e Malformações Congênitas Múltiplas; uma (01), Síndrome de Rubinstein-Taybi e uma (01), casal com Abortamento de Repetição, sem etiologia definida.

\subsection{Método}

\section{a) Definição do método de estudo}

Para realizar este estudo, optamos por trabalhar com o método clínico, utilizando a entrevista semi-estruturada. Optamos pelo uso da entrevista, uma vez que, para atender aos objetivos propostos, seria necessário apreender um momento específico da vida dessas famílias, o que só seria possível através de relatos do que cada um deles vivenciou.

$\mathrm{O}$ estudo constou de três fases:

$1^{\text {a }}$ - entrevista realizada antes da consulta inicial na Genética;

$2^{\mathrm{a}}$ - entrevista após o terceiro atendimento e

$3^{\mathrm{a}}$ - entrevista um mês após ter sido realizado o aconselhamento genético.

\section{b) Instrumento de levantamento dos dados: rotei- ro de entrevista semi-estruturada}

Visando atender aos objetivos propostos, foram elaborados dois roteiros de entrevista semiestruturada. O roteiro para a primeira entrevista continha os seguintes tópicos: dados pessoais, dados sobre o nascimento, informação sobre o Serviço de Genética, conhecimento sobre o problema, aspectos emocionais e informações gerais sobre o casal. Para a segunda e terceira entrevistas, alguns tópicos foram retirados - dados pessoais, dados sobre o nascimento, etc. - e acrescentados os seguintes tópicos: informações recebidas até o momento, dúvidas que possuem e uso de métodos anticoncepcionais.

\section{c) Análise dos dados}

Inicialmente, realizamos uma leitura atenta dos relatos dos pais, tendo por base as questões que orientaram este estudo. Os conteúdos dos relatos foram agrupados em temas comuns, dentro dos quais, muitas vezes, se reagruparam no que denominamos categoria.

O primeiro tema - como fiquei sabendo - engloba cinco categorias: omissão de informação; linguagem inadequada; minimização de informação, linguagem negativista e informações fornecidas no momento inadequado.

No segundo tema - reações dos pais - os conteúdos dos relatos foram agrupados nas categorias choque, agressividade e desejo de morte.

Quanto aos sentimentos vivenciados pelos pais, terceiro tema analisado, os conteúdos dos relatos foram agrupados em três categorias: sentimento de negação, raiva e sentimento de culpa.

A seguir, apresentaremos os três grandes temas e suas respectivas categorias, exemplificados pelas falas dos pais e uma breve discussão sobre os mesmos.

\section{RESULTADOS E DISCUSSÃO}

Como fiquei sabendo: a percepção dos pais a respeito das primeiras informações sobre a deficiência do filho. 


\section{a) Omissão das informações}

Ao analisarmos os relatos constatamos que os pais consideram as primeiras informações recebidas sobre o problema do filho como insuficientes, pouco claras e/ou pouco objetivas. São encaminhados para os serviços especializados sem que lhes seja explicado o motivo.

"Criança nasceu com 2030 kg, a médica encaminhou para a Genética”, (S. de Silver-Russel F1) *.

Outras vezes, os profissionais atêm-se a um ou mais sinais clínicos que compõem a síndrome e/ou a aspectos do desenvolvimento, sem, no entanto, explicarem o real significado, como demonstra o relato da mãe de uma criança diagnosticada como portadora da Síndrome de Beckwith-Wiedemann: "Ele teve hérnia no intestino e a médica das Clínicas Velha falou que ele tem problema na língua, ele tem língua grande".

A falta total de informações também pode ser observada no relato de duas mães.

"Fala que a criança ia ser normal. Ah! Não sei. Ninguém fala nada, o nome. Só do olho, do risquinho" (S. de Down-F4).

"As médicas não falam nada do que ele tem, só que ele tá indo bem". (S. de Beckwith-Wiedemann F2).

Atitudes como essa são comuns e, segundo Regen ${ }^{(7)}$, demonstram o despreparo emocional dos profissionais, sua ansiedade frente à situação, levando-os a transferirem para terceiros a responsabilidade da comunicação da doença. Agindo assim, retardam, por vezes, o processo de aceitação, o início dos atendimentos e, principalmente, a reestruturação da dinâmica familiar.

\section{b) Linguagem inadequada}

$\mathrm{O}$ uso de linguagem inadequada com palavras que não são de uso habitual no vocabulário dos pais, e o uso frequiente de terminologia científica, como "síndrome", "cariótipo", "cromossomo", "cardiopatia", entre outros termos, são fatores que dificultam a compreensão correta das informações, como podemos observar nos relatos dos pais de duas crianças com Síndrome de Down e da mãe da criança com Síndrome de Rubinstein-Taybi.

"A médica falou que ela tem mongolismo $e$ quem cuida é aqui" (s. DownF5).

*As famílias foram numeradas para identificação.
"Fomos encaminhados pela Dra. para fazer cariótipo" (S. Down-F4).

"Os médicos falaram, um problema na hora que os espermatozóides encontra o ovo" Não entendi. (S.Down-F4)

"Quero saber o motivo disso, cardiopatia". (S. Rubinstein-Taybi-F10).

Muitas vezes, o entendimento incorreto das informações faz com que os pais criem fantasias e expectativas errôneas da real condição da criança, gera ansiedade e angústia, o que, às vezes, dificulta ainda mais a compreensão das informações.

\section{c) Minimização do problema}

Informar aos pais, simplificando as informações e/ou subestimando os aspectos negativos e a gravidade do quadro, é a maneira pela qual alguns profissionais dão a notícia aos pais, como demonstram os seguintes relatos.

"Quando ele nasceu, quinze dias depois, o médico auscultou sopro. Encaminhou para a cardiologia que pediu eco; detectou tetralogia de Fallot. O cardiologista solicitou consulta na Genética, porque ele (criança) tem dedo tortinho e muito cabelo". (S. Rubinstein-Taybi - F10).

"Os médicos falaram que não é nada da gravidez ... Mandaram para a Genética" (Abortamento de Repetição-F7).

Ao reduzirem o problema aos sinais clínicos que a criança traz, sem informar o que eles significam ou podem significar, e a possível "gravidade" do quadro, os profissionais estão minimizando a importância e os significados dos indicadores, levando os pais a terem uma percepção irreal do que está acontecendo, dificultando a aceitação do diagnóstico.

\section{d) Linguagem negativista}

Ao fornecerem as informações, muitas vezes, os profissionais ressaltam os aspectos negativos do quadro, criando, nos pais, imagem negativa do filho.

"A médica explicou que ia ter que estudar em escola diferente ... Não seria igual aos meus outros filhos, que ela vai demorar para andar, falar...

Quando falaram que ela era assim, achei que era igual criança da A.P.A.E. Quando a médica foi falando, via a $\underline{\mathrm{N}}$, toda encolhidinha, com a mão que não ia pegar nada, sem poder pisar no chão". (S. Down - F5). 
"Disse que ele tem Entofia Congênita Duchenne, ele explicou que piora, assim oh. Ele estava andando, não caía, agora cai. Antes levantava sozinho, agora precisa segurar ... O médico da escola disse que ele vai andar até nove anos e que depois não anda mais". (Distrofia Muscular Progressiva Duchenne - F6).

Embora, em alguns casos, as informações transmitidas sejam reais, informar de forma destrutiva, ressaltando somente os aspectos negativos do quadro e utilizando termos que tenham conotações negativas, pode levar os pais a uma expectativa errônea sobre o desenvolvimento da criança. Essa percepção pode dificultar não só o processo de aceitação, como, também, retardar o oferecimento dos necessários atendimentos especializados e dificultar o estabelecimento das relações afetivas, exacerbando o sentimento de rejeição.

\section{e) Momento inadequado}

O momento, em que se deve informar os pais, tem sido discutido na literatura ${ }^{(7,9,10)}$. A notícia sobre a deficiência do filho, realizada em um momento inadequado, pode desencadear e fortalecer os sentimentos de revolta e de raiva, como demonstra o relato do pai de uma criança com Síndrome de Down.

"Eu estava lá para ver a criança, quarenta e cinco minutos depois que ela tinha nascido, e a "égua" falou que ela tinha Down, que não ia andar, que não ia falar... Pedi para não falarem nada para ela (mãe), esperar o dia seguinte, quando eu estivesse junto; mas não, ela (médica) falou antes de ir embora ..."

"Quando a médica falou, fiquei chocada. Telefonei para ele (esposo), pedi para vir para o Hospital". (s. Down - F4).

"Chorei a noite toda, esperava encontrar meu filho morto quando chegasse ao Hospital". (s. BeckwithWiedemann-F2).

É necessário que o profissional compreenda a dor dos pais e respeite o momento de cada casal, evitando, assim, o rompimento do vínculo médico-paciente, pois, assim, a família fica órfã, muitas vezes sem condições de perceber que necessita de ajuda ou, então, sem saber onde buscá-la, uma vez que desconfia de todos.

Como observamos, a forma como os pais entram em contato com a notícia da deficiência do filho é diversificada.
Ao se fazer a análise dos relatos, é necessário que se considere, em primeiro lugar, o estado emocional dos pais, ao receberem as informações. É provável que, devido à ansiedade, à angustia e ao choque, muito do que foi dito será exacerbado, ou, então, parte do conteúdo não será captado.

Outro fator a ser considerado diz respeito à questão da lembrança das informações recebidas. De acordo com Evers-Kiebooms ${ }^{(9)}$, falhas de memória podem ocorrer, seja devido ao tempo que se passou ou ao próprio estado de ansiedade dos pais.

É importante que se considere o fator "lembrança de informações"; entretanto, a falta de lembrança das mesmas pode também significar um mecanismo de defesa dos pais, que se recusam a lembrar um fato que lhes é doloroso e do qual ainda não se recuperaram.

A forma como a família entra em contato com a notícia pode desencadear reações diversas, criando expectativas em relação ao futuro da criança, e comprometer as ações necessárias para o seu bom desenvolvimento.

É importante comunicar de maneira adequada, oferecer as informações claras e objetivas, utilizando linguagem acessível aos pais, propiciando-lhes condições de discutirem suas dúvidas.

\section{REAÇÃO DOS PAIS}

A descoberta do nascimento de um bebê portador de anomalia pode causar "stress" na família; várias reações podem ocorrer, desde a extrema apatia ao extremo desespero, da neutralidade ao envolvimento total.

Nossos dados mostram que a grande maioria da amostra, seis mães e três pais, perceberam-se em estado de choque, quando lhes foi dada a notícia sobre a condição anômala do filho.

\section{a) Choque}

"Levei um choque. Porque não é igual ... comecei a chorar". (S. Down - F5)

"É um choque, a gente fica traumatizada, mas passa". (S. Down - F4)

O choque foi definido por Drotar et al. ${ }^{(11)}$ como uma interrupção abrupta, uma quebra de equilíbrio usual. É a reação mais freqüentemente relatada pelos pais, neste estudo, demonstrando que o impacto da 
anomalia de um bebê por si só é desestruturador, independente do tipo de deficiência ou gravidade que possa acarretar.

Esse período é, muitas vezes, acompanhado de choro, de condutas irracionais, sentimentos de desamparo e tristeza ${ }^{(3)}$. Os pais sentem-se sozinhos, desapontados, como se ruísse o mundo que construíram.

\section{b) Agressividade}

"Quase bati nela (médica), joguei pela janela. A sorte foi que eu passei mal, quase desmaiei, pressão caiu". (S. Down - F4)

"Fiquei com a cabeça atordoada, fiquei assim, quando fiquei sabendo". (S. Down - F3)

Reações de agressividade para consigo mesmos e para com os outros (profissionais, cônjuge, vizinhos, etc.), acrescidas de manifestações fisiológicas, foram relatadas, demonstrando, novamente, o quão intenso é o impacto, afetando não só o equilíbrio emocional, mas, também, o equilíbrio físico dos pais.

\section{c) Desejo de morte}

"Chorei a noite toda, esperava encontrar meu filho morto quando chegasse no Hospital". (S. Beckwith-Wiedemann - F2)

"Fiquei triste, também pensei que ele fosse morrer". (S. Beckwith-Wiedemann - F2)

"Fiquei abalada, chorei. Para falar a verdade eu dei graças a Deus. Estava caindo. Não pensava em ser mãe, foi melhor. Ele (marido) falou que se a criança sobrevivesse ele ia me deixar, ia embora. Meu pai ia encher o saco" (referindo-se ao filho natimorto). (Sirenomelia - F8)

Reações de desespero, nas quais o desejo da própria morte, ou da morte do filho, é percebido como a solução para o término do sofrimento pelo qual estão passando, são relatadas pelos pais. Embora inicialmente tragam alívio, tais pensamentos, quase sempre, desencadeiam sentimentos de culpa e remorso.

\section{SENTIMENTOS VIVENCIADOS}

Passado o impacto inicial, marcado predominantemente pela reação de choque, os pais vivenciam os mais variados sentimentos, até que se reestabeleça o equilíbrio novamente. Negação, culpa, tris- teza e ansiedade são algumas das reações emocionais relatadas por eles.

\section{a) Negação}

"No fundo, acho que ele vai se desenvolver, não espero que ele tenha 1,80m, mas não vai ser anão ... Eu não me preocupo mas acho que é questão de tempo, eu também fui miudinha quando criança". (S. Silver-Russel - F1)

"Ele tem olho puxado. Acho que ele tem o olho puxado, apesar de que meu irmão caçula é idêntico a ele. Se comparar com outra criança que conheço, também não vejo diferença, ele é novinho e não dá para perceber. Acho que é um pouco novinho, mas nessa idade é assim mesmo". (s. Down - F3)

"Ele é magrinho, mas acho que é por causa do coração. Não senta, não sustenta a cabeça ainda, mas é por causa do problema do coração."

(S.Rubistein-Taybi - F10)

A negação é o mecanismo de defesa mais freqüentemente utilizado pelos pais. A recusa em aceitar o diagnóstico nem sempre aparece explícita nos relatos. Identificar traços fisionômicos (patológicos) da criança com os traços característicos da família; justificar o "atraso" de desenvolvimento em função de um problema orgânico ou simplesmente ter convicção de que o que foi falado não acontece, são algumas das formas de manifestar a negação.

A intensidade e a extensão dessa fase são variáveis, tanto de casal para casal quanto de pessoa para pessoa. Entretanto, ela não costuma ser caracterizada por um período muito longo, mas, por um período de transição, que será substituído por sentimentos menos radicais.

Segundo Oliveira ${ }^{(10)}$, no período em que vivenciam esse sentimento, os pais adotam a "fuga da realidade", usando de escapismos para se justificarem.

Essa fase é marcada pela busca compulsiva dos pais pela confirmação do diagnóstico, levando-os a fazerem verdadeiras peregrinações aos consultórios médicos. Para Mannoni ${ }^{(12)}$, a mãe vai a numerosos especialistas, não à procura de um diagnóstico, mas desejando que sua pergunta nunca receba resposta, para que possa continuar a fazê-la.

É importante que os profissionais não considerem essa fase como condenável, mas como um mecanismo de defesa, necessário ao processo de reestruturação. 


\section{b) Raiva}

"A pneumonia é culpa da médica. Desidratação também”. (S. Down - F4)

"A médica olha a mão, fala que é mongol. Isso porque não é filho dela. A mão dele parece com a minha". (S. Down - F4)

Sentimentos de raiva aparecem, uma vez que os pais sentem-se logrados por seus sonhos e projetos que não serão realizados. A raiva pode propagar-se em várias direções, atingindo profissionais, cônjuges, parentes e até mesmo vizinhos. É um período dos mais difíceis de ser lidado, principalmente pelos profissionais e cônjuges, que não se encontram preparados para serem o alvo da agressividade. Requer a compreensão de todos, para que não julguem os pais, analisem e tenham consciência do motivo dessa raiva e não a assumam em termos pessoais.

Kluber-Ross ${ }^{(13)} \&$ Smith $^{(8)}$ enfatizam que é importante para os pais que os profissionais e os outros aprendam a tolerar e a compreender a raiva que os pais estão sentindo. Permitir-lhes externar esses sentimentos e propiciar-lhes o alívio de que necessitam, dando-lhes condições de se reestruturarem, é a forma mais eficaz de efetivamente ajudá-los.

\section{c) Culpa}

"A gente pergunta: por que aconteceu comigo?”. (S. Down - F4)

"Quando a gente vai ter um filho quer tudo perfeito, com saúde. Não estamos preparados para isso. Por que eu?" (s. Down - F4)

"Você não imagina que vai acontecer com você". (Abortamento de Repetição - F7)

É comum os pais expressarem sentimento de culpa. Há uma necessidade de saber por que aconteceu com eles e uma preocupação de que eles mesmos foram os causadores do problema. Culpam-se por atos passados ou presentes, pelos quais estão sendo agora castigados. A sensação de culpa, de castigo, é maior quando existe um fato que a pessoa julga errado e/ou é visto pela sociedade como condenável. Muitas vezes, transferem a "culpa" para terceiros: cônjuges, profissionais, parentes e vizinhos, diminuindo assim suas responsabilidades.

A necessidade de saber de quem é a culpa é vista por Regen et al. ${ }^{(7)}$ como uma forma de explicar o "castigo" que lhes estaria sendo imposto. Esse sen- timento aparece mais freqüentemente nas mães, fato explicado por serem elas que "carregam" a criança. Porque se sentem responsáveis pela nutrição, pelo bem estar físico e psicológico, conseqüentemente, sentem-se culpadas por algo errado que ocorreu.

Os pais sentem necessidade de saber a razão do que aconteceu com eles, em detrimento das explicações científicas que possam ser dadas. Encontrar explicações que os satisfaçam faz parte do processo de aceitação e reestruturação da família.

\section{CONSIDERAÇÕES FINAIS}

De acordo com os dados obtidos, pode-se concluir que:

1. Independente do quadro clínico e do diagnóstico, os pais, sem exceção, sofrem o impacto com a notícia de que seu filho é portador de uma anomalia. São levados a um processo de sofrimento agudo, entram em período de enlutamento: choram a perda do filho esperado.

2. A linguagem utilizada pelo profissional e a forma como são passadas as informações, além da própria complexidade delas, podem desencadear reações emocionais intensas e interpretações errôneas sobre o diagnóstico.

3. É importante comunicar a notícia ao casal de maneira adequada, oferecendo-lhe todas as informações sobre o problema, de forma clara e objetiva, com uma linguagem que lhe seja acessível, propiciando-lhe, assim, condições de discutir abertamente suas dúvidas.

4. O sentimento de culpa aparece independentemente da gravidade do caso. Os pais sentem necessidade de encontrar uma explicação para o acontecido: culpam-se a si mesmos ou a terceiros, sentem necessidade de explicar o que parece um "castigo" que lhes está sendo imposto.

5. A manifestação dos sentimentos, intensa ou não, deve ser considerada pelos profissionais como normal, necessária ao processo de reestruturação e de equilíbrio familiar.

6. É essencial que se dêem às famílias condições para se estruturarem e se ajudarem mutuamente, auxiliadas por profissionais da área de saúde mental que, efetivamente, compreendam as fases por que estão passando, respeitando-se cada um dos momentos do casal. 
PETEAN EBL \& PINANETO JM de. Investigations in genetics counselling: the impact of the first notification - parental reaction to a deficiency. Medicina, Ribeirão Preto, 31: 288-295, apr./june 1998.

ABSTRACT: The objective of the present study was to determine the impact caused by notification of genetic deficiencies and/or anomalies on the parents of affected children, as well as their reactions and feelings. The study was conducted on tem families referred to the Medical Genetics Outpatient Clinic of the University Hospital,Faculty of Medicine of Ribeirão Preto, University of São Paulo, for diagnosis and counselling.

The emotional impact of the news was found to be very strong,triggering varios reactions such as shock and agressiveness.Guilt,denial and anger are some of the feelings experienced by the parents. The news is almost always given in an inadequate manner, preventing a proper understanding of the diagnosis.

We may conclude that, regardless of the clinical picture, the parents feel the full impact of the news that their child has a genetic deficiency and/or anomaly. The suffering process is acute, with the parents going through a morning period for the loss of the expected child.

UNITERMS: Genetic Counselling. Family. Psychology. Child, Exceptional.

\section{REFERÊNCIAS BIBLIOGRÁFICAS}

1 - SOIFER R. Psicologia da gravidez parto e puerpério. Editora Artes Medicas, Porto Alegre, 124 p.,1986

2 - BINDA W. Da díade conjugal à tríade familiar. 1992. (Material Didático não publicado).

3 - CHILDS RE. Maternal psycological conflicts associated with birth of retarded child. Matern Child Nurs J: 175-182,1980.

4 - IRVIN NA; KENNELL JH \& KLAUS M. Assistência de los padres del niño con malformación congénita. In: WARKANY J. Congenital malformation: notes and comments. Year Book Medical Publications, Chicago, p. 156-187, 1975.

5 - MARCHEZI SRSB. A criança e a família: O problema do retardamento mental. Tese de Doutorado, Faculdade de Filosofia, Ciências e Letras da UNESP, Araraquara, SP. p.01$234,1973$.

6 - TELFORD CW \& SAWREY JM. O indivíduo excepcional. Zahar Editores, Rio de Janeiro, 658 p., 1978

7 - REGEN M; ARDORE M \& HOFFMAN VMB. Mães e filhos especiais: Relato de experiências com grupos de mães de crianças com deficiência. CORDE, Brasília, 1993, 137 p.
8 - SMITH P. Vocês não estão sozinhos. Mensagem da A.P.A.E. 13 (39):34-39.1990.

9 - EVERS-KIEBOOMS H \& van den BERGHE H. Impact of genetic counseling a review of published follow-up studies. Clin Genet 15: 465-474, 1979.

10 - OLIVEIRA AJ. A Família frente ao excepcional. Fundação Catarinense de Educação Especial, Florianópolis, 1988. Monografia - Apostila.

11 - DROTAR D et.al. Parental attachment, congenital malformations, grief, bonding, crisis counseling. Pediatrics 56: 710-716, 1975.

12 - MANNONI M. A criança retardada e a mãe. Martins Fontes, São Paulo, 151 p., 1985.

13 - KLUBER-ROSS E. Sobre a morte e o morrer. Martins Fontes, São Paulo, 299 p., 1992.

Recebido para publicação em 04/12/97.

Aprovado para publicação em 03/04/98. 